\title{
The Management of Secondary Water Supply in China
}

\author{
Shi Hu Shu * \\ National Engineering Research Center (South) for Urban Water Resource , \\ No. 230, Xuchang Rd, Shanghai 200082, China \\ ssh314@126.com
}

Keywords: Secondary water supply; Water quality; Management; Ownership of property.

\begin{abstract}
The paper analyzes the management status and the problems existing in the urban secondary water supply systems in China. New management mode of the secondary water supply system is put forward. The contents, difficulties and measures of the new idea of secondary water supply management are given, which may be used for reference for urban secondary water supply. Maintenance and updating the facilities of secondary water supply, strict supervision on the social property enterprises, establishing the idea of administration by law. When formulating administrative regulations in according higher-level law, administrative and legal management are not contradictory, and the problem of secondary water supply can be solved.
\end{abstract}

\section{Introduction}

Due to pollution in second water supply system (SWSS) which can be seen in Figure 1. and Figure 2., nine renovation alternative plans were proposed and comprehensive evaluations of different plan were presented. Comparisons of advantages and disadvantages among the plans of SWSS renovations provided solid foundation for selecting the most appropriate plan for engineering projects.

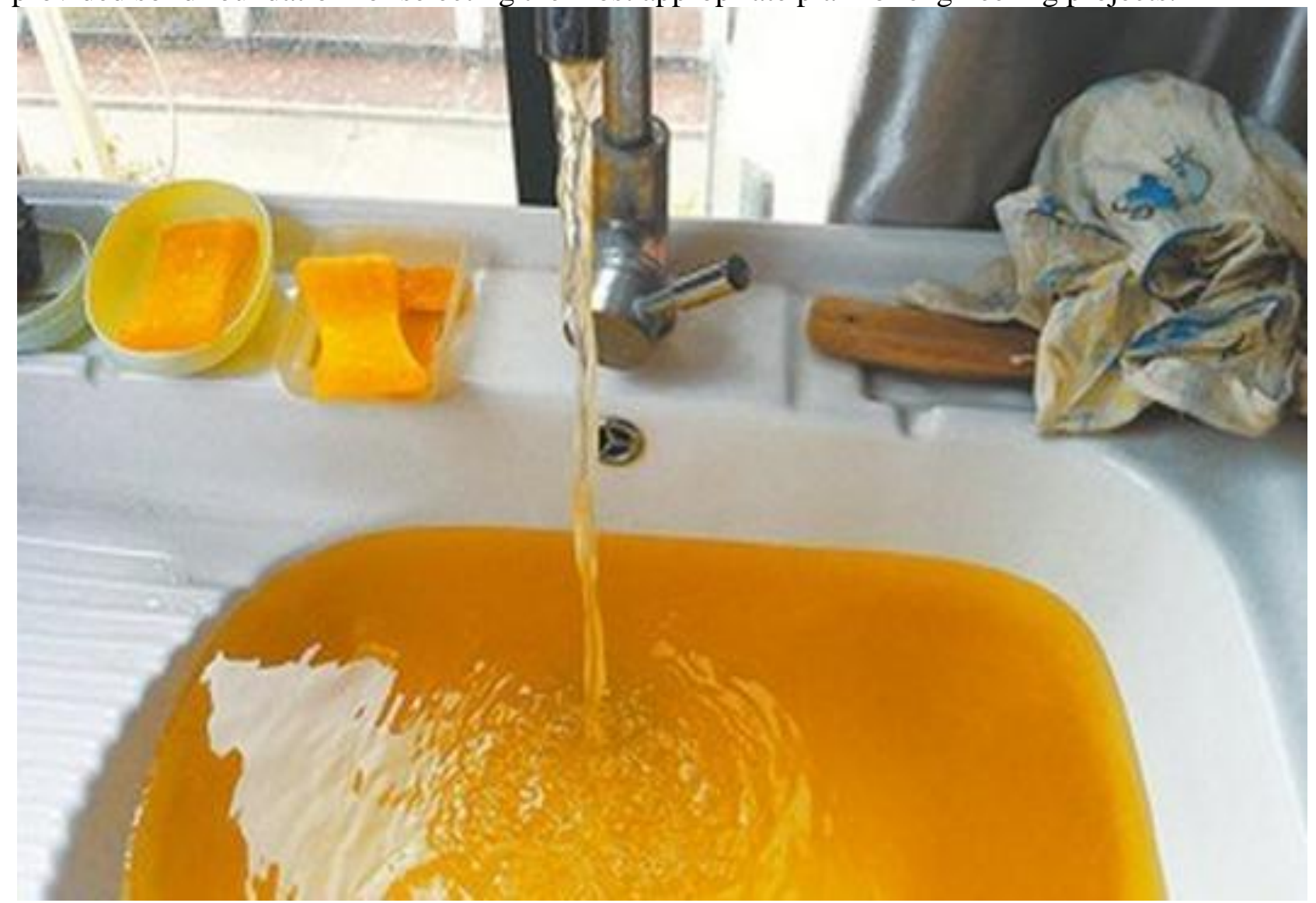

Figure. 1 Tap water pollution in SWSS 


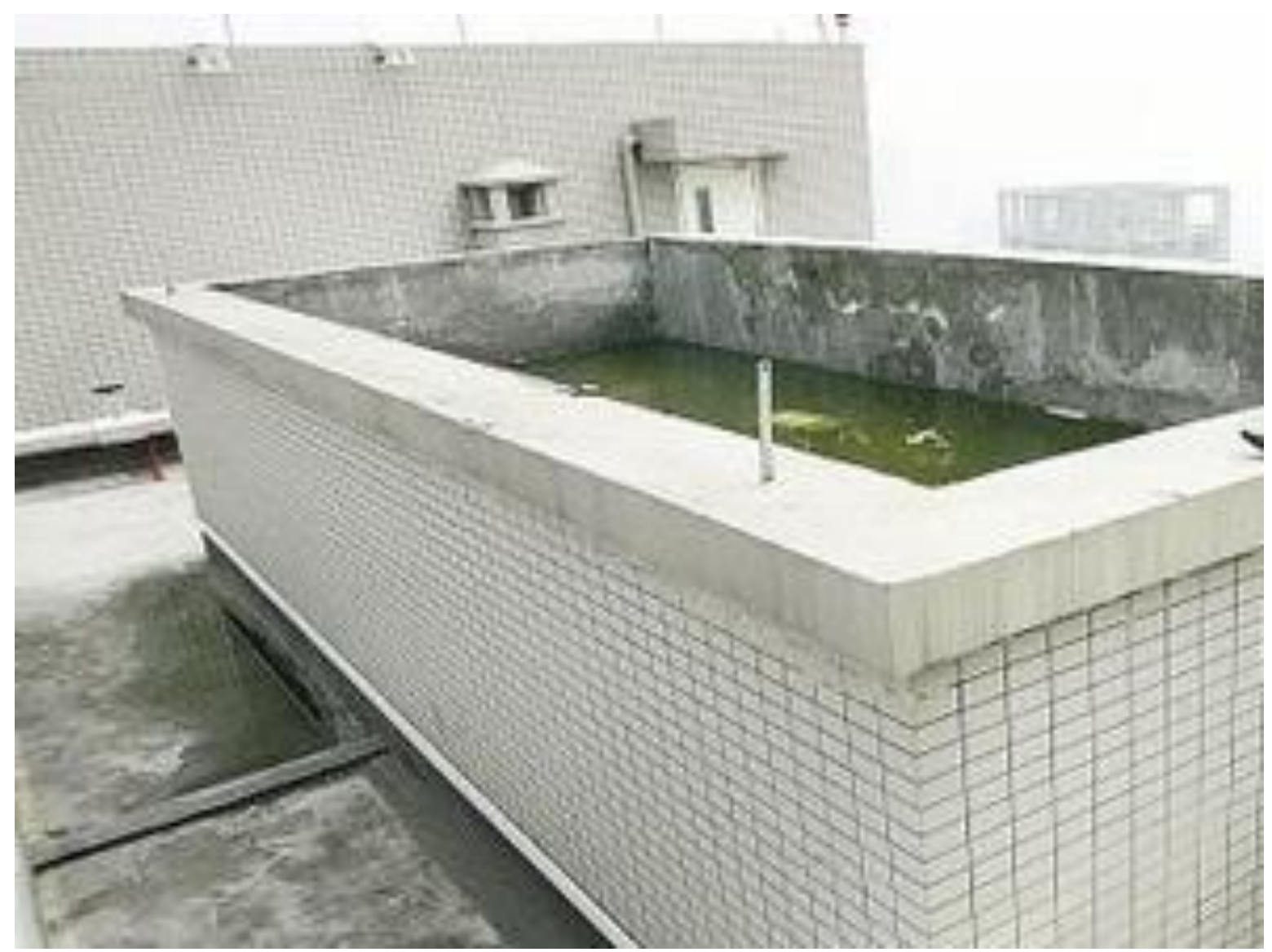

Figure. 2 Tank water pollution in SWSS

\section{Problems and Answers}

On the surface, the problem of secondary water supply is bad water quality, poor maintenance service, poor equipment management, sometimes no water or with low pressure and so on. It is always be complaint by users, government and media focusing on, the water company's entanglements point.

In history, there was not the problem of secondary water supply, which becomes popular in nearly two decades. 128 years ago, drinking water was introduced into China. The management of water system is according to water meter trade measurement: the outside is public water system( be called municipal water supply), belonging to one part of urban infrastructure, and managed by urban water sector; the inside is the property right of the users, who can build , use and manage it. This model's jurisprudence base is real right. From the liberation to 1970s, China also used this model. But when most private real estate became government owned, both side of water meter became nationalized. The representatives are public utilities bureau and real estate bureau, and the representative units are water companies and housing management. However, some housing management is not in charge of the public pipeline, which belongs to housing management and is inseparable with the house. When the users get the poor water and find housing management, housing management lets them to find the water company. The government coordinates in this question. In 1990s, the reform lets housing management privatization, and the binding force from government greatly reduced. The problem of secondary water supply has become increasingly prominent.

The key to solve the problem is management.

In this period, there is the problem in management roll. Because of the difference between the local regulation and government law in the management of secondary water supply, there are two methods: the one is that property ownership is determined by management responsibility, the other one is that the attribution of responsibility is determined by administrative regulation. In different place with 
different management method, even in mass, secondary water supply becomes the weakness of water quality management of urban water supply.

Being mass in management roll causes casualness in management object. Therefore, when deciding the management department, the phenomenon that "favorable to compete, non-profit phase push" appears.

When carding the management cost, operation and maintenance cost is always ignored or procrastination. So, management of secondary water supply becomes difficult.

The idea and legal basis of management of secondary water supply is that first of all, make sure that the ownership of property, and then clear usufruct, dispositions and associated undertakings(obligations), and these rights, benefits, responsibilities can't be separated. According to the provision, if the thing belongs to you, it is not permit that you are noncommittal because of quitclaim. The water company has its professional advantage to contract with management and maintenance business associated with its profession. Completely by the rules of <Property Law> and basing on the <Contract Law>, the water company can contract the business in the society. Under the government departments' guidance, the company also can equitably access to franchise, and management secondary water supply. However, all parties must be subject to the principle that rights, benefits and responsibilities are consistent. The water company can't own the secondary water supply, or that would infringe the integrity of the property owner. The house with an incomplete property right will bring a lot of unexpected larger social problems.

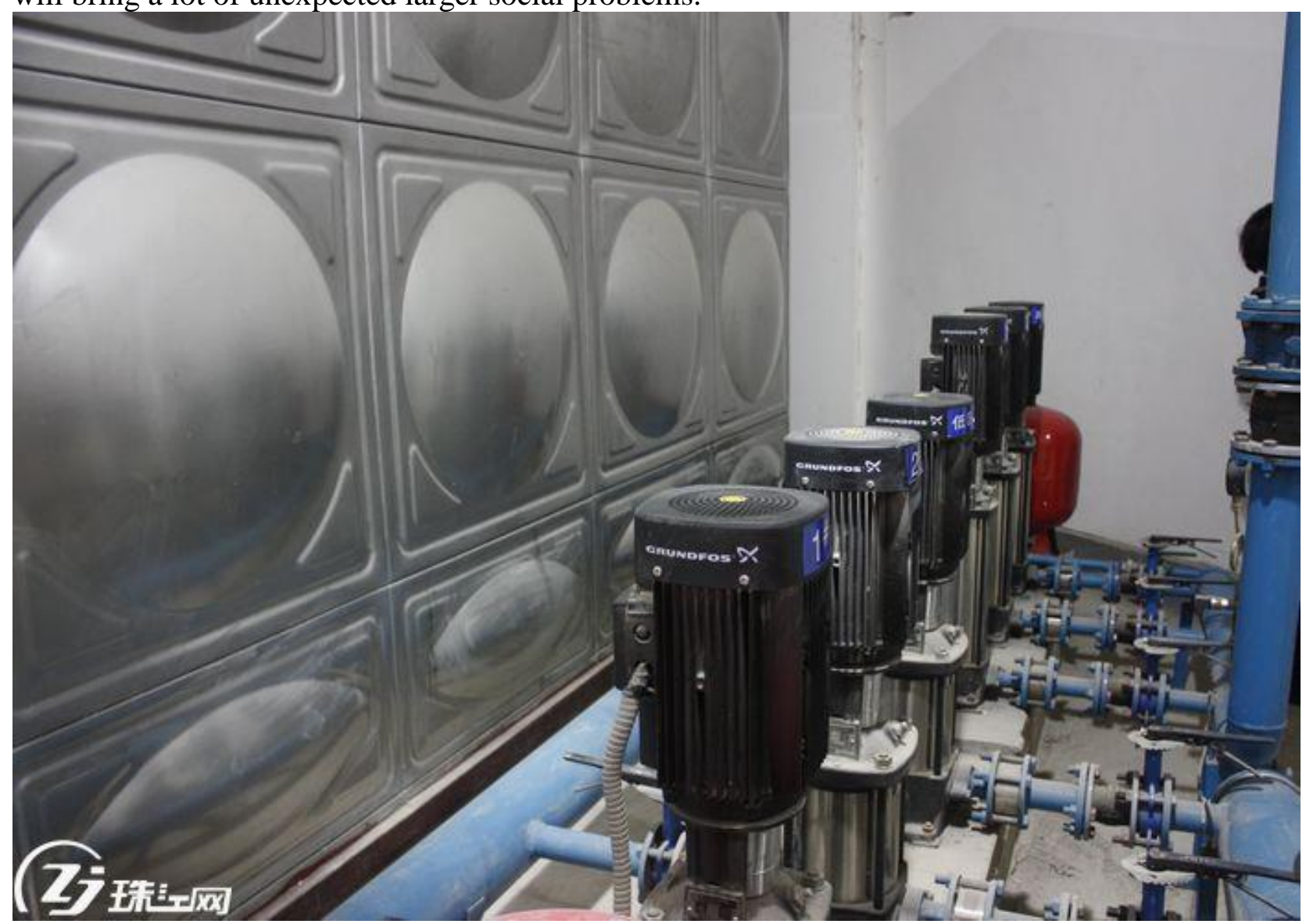

Figure. 3 The reconstruction of facilities in SWSS

\section{Summary}

Maintenance and updating the facilities of secondary water supply, strict supervision on the social property enterprises, establishing the idea of administration by law. When formulating administrative regulations in according higher-level law, administrative and legal management are not contradictory, and the problem of secondary water supply can be solved. 


\section{References}

[1] X.M. Zheng, The problem of secondary water supply management in China. Urban water supply. 2012, 6(5), 1--5.

[2] Y.M Tian, Y.J. Si, H. Li, M.F. WU. Evaluation and optimization of secondary water supply system renovation. Journal of Zhejiang University. 2007-9

[3] Z.S. Dong. Discussion on Rebuilding of Guangzhou Residential Secondary Water Supply System. China Water \& Wastewater. 2006-14 